\title{
Treating Dual Diagnosis Patients: Challenges and Opportunities
}

Robert H. Howland, M.D.

Western Psychiatric Institute, University of Pittsburgh

Follow this and additional works at: https://jdc.jefferson.edu/jeffjpsychiatry

Part of the Psychiatry Commons

Let us know how access to this document benefits you

\section{Recommended Citation}

Howland, M.D., Robert H. (1990) "Treating Dual Diagnosis Patients: Challenges and Opportunities," Jefferson Journal of Psychiatry. Vol. 8 : Iss. 1 , Article 5.

DOI: https://doi.org/10.29046/JJP.008.1.002

Available at: https://jdc.jefferson.edu/jeffjpsychiatry/vol8/iss1/5

This Article is brought to you for free and open access by the Jefferson Digital Commons. The Jefferson Digital Commons is a service of Thomas Jefferson University's Center for Teaching and Learning (CTL). The Commons is a showcase for Jefferson books and journals, peer-reviewed scholarly publications, unique historical collections from the University archives, and teaching tools. The Jefferson Digital Commons allows researchers and interested readers anywhere in the world to learn about and keep up to date with Jefferson scholarship. This article has been accepted for inclusion in Jefferson Journal of Psychiatry by an authorized administrator of the Jefferson Digital Commons. For more information, please contact: JeffersonDigitalCommons@jefferson.edu. 


\title{
Treating Dual Diagnosis Patients: Challenges and Opportunities
}

\author{
Robert H. Howland, M.D.
}

\section{INTRODUCTION}

The use and abuse of drugs and alcohol have recently gained greater attention both from the public and the medical profession. Despite increasing cognizance of its unfortunate consequences, substance use has become a more pervasive element of contemporary society. As substance abuse has come to affect more segments of the population, it is not surprising that this problem also has affected the mentally ill. Awareness of the mentally ill substance abuser has grown, although this population has not been well studied or well served by the mental health system. These dually diagnosed patients often are depicted as the square pegs of psychiatry, not quite fitting into the round hole of mental health treatment. The reason for this is clear. Because of the current structure of the mental health service delivery system, psychiatric and substance abuse services are provided almost exclusively by independent systems $(1,2)$. As a result, those patients who are perhaps most in need of treatment are most likely to fall through the cracks of the system. Providing services for this group of patients represents a clinical and administrative challenge, which has not been adequately addressed by the psychiatric profession. In this paper, I suggest that psychiatrists can accept greater responsibility for working with the dually diagnosed, and that this responsibility could begin with the psychiatrist-in-training. Although the problem may be difficult to overcome, psychiatry is in a unique position to accept this responsibility, effect changes in the system, and have a positive impact on the lives of patients with dual diagnoses.

\section{CLINICAL PROBLEM}

Although clinical experience may give a rough idea of the number and types of patients with dual diagnoses, there are a small number of surveys that define the extent of this problem more completely. Many of the studies examine specific patient populations, such as psychiatric inpatients (3) or persons who present for substance abuse treatment (4), so that the results are not easily generalized. However, most studies do support the clinical impression that individuals with a psychiatric disorder are at higher risk of also having or developing a substance abuse disorder and vice versa. Comorbidity rates vary considerably between studies depending on the population sample, but have 
been reported to range from six percent to as high as 80 percent $(3-10)$. Thus, by considering the dually diagnosed as a single diagnostic category, these results suggest that clinicians are much more likely to encounter a patient with this problem than one with just schizophrenia or bipolar disorder alone, for example.

The variability reported in the rates of comorbidity is in part due to the kinds of patients studied, suggesting that the dually diagnosed are a very heterogeneous group. Historically, clinicians have felt that the dually diagnosed represent patients who are primarily personality-disordered, especially sociopathic personalities (11), or who are severely and chronically mentally ill (12). However, more comprehensive studies show that this is not entirely true and that all types of psychiatric disorders are significantly represented among patients with dual diagnoses $(4-6,13)$.

The dually diagnosed also are distinguished in many respects by their clinical characteristics. These patients may be more difficult to work with $(5,14)$, are more noncompliant with, and less responsive to treatment (14-18), more frequently use emergency services $(13,19)$, and are at increased risk for suicide and violence $(14,20-22)$. The clinical picture that emerges is not very appealing to clinicians, especially psychiatrists-in-training, although it is important to realize that this picture is a composite drawn from many different experiences with psychiatric patients who are substance abusers. Substance abuse may not be recognized in many patients who are otherwise engaged in treatment $(2,5,6,9,13)$, although it may greatly contribute to their morbidity. Many of these patients also may be relatively better functioning individuals who are troubled by interpersonal or family difficulties and are not significantly or chronically disabled. They may be treated with individual psychotherapy or family therapy, perhaps using adjunctive medications, but do not do well because of their unrecognized substance abuse. As a result, they may become dissatisfied with and drop out of treatment, go on to develop a chronic course, or be terminated as a treatment failure.

\section{TRAINING ISSUES}

For the psychiatrist-in-training, dual diagnosis patients pose several apparent problems related to training. However, lack of exposure to these patients is not one. As noted above, many psychiatric patients who are substance abusers present to emergency rooms in crisis and at odd hours, and often are admitted to acute psychiatric inpatient units. They may be seen in the general psychiatric clinic because they are not appropriate for specialty services or are unwanted by private practitioners. In each of these situations, the primary responsibility for care often falls on the psychiatric resident.

One issue that is important to the psychiatrist-in-training in working with the dually diagnosed is the lack of formal training experiences in substance abuse evaluation and treatment. Most medical schools and residency programs 
have minimal educational opportunities in this area. They usually take the form of electives for those who are interested and motivated and generally involve patients with "pure" substance abuse disorders rather than dual diagnoses. Without adequate training, treating the substance abuser can be as difficult as treating any other psychiatric illness. This is especially true with a patient who has both conditions.

Another issue that is equally important is whether the dually diagnosed are appropriate training "cases". Because of their substance abuse, they may not be thought of as good candidates for psychotherapy or even pharmacotherapy. If they are difficult patients to work with, then they may be terminated from or allowed to drop out of treatment, using the substance abuse as a rationale and perhaps suggesting that substance abuse treatment would be more helpful or appropriate for the patient. Of course, it is likely that a substance abuse clinician may find the presence of a psychiatric disorder to be an equally complicating factor in treatment.

The importance of these issues should not be minimized. However, they also should not deter psychiatrists from making a commitment to providing treatment for the dually diagnosed, especially when they have few alternatives available to them. Rather than refusing to accept them for treatment, or letting them drop out of treatment with little effort to engage them because of inexperience and lack of training, psychiatric training should encompass the evaluation and treatment of substance abuse. Ongoing supervision and instruction typically is provided throughout the period of training in psychiatry and could easily include substance abuse disorders, rather than limiting this training to a single rotation or elective. In addition, it also is important to seek consultation from those professionals who can provide assistance in working with these patients, in much the same way that other consultants are used for difficult clinical situations. For example, this might involve active collaboration with a substance abuse counselor or treatment facility.

Finally, the training value of the dual diagnosis patient cannot be overemphasized. Because of their sheer numbers alone, it is inconceivable that any psychiatrist will be able to avoid them in their clinical practice. Moreover, how psychiatrists practice after training depends to a large extent on their experiences during training. Therefore, avoiding these patients and neglecting to learn about substance abuse disorders makes it unlikely that they will ever feel comfortable with or capable of treating them. In the approach to treatment, there is much that can be learned from patients with dual diagnoses. For example, a broad array of biological and psychosocial approaches to treating patients with schizophrenia, social phobia, or borderline personality are now available to psychiatric residents. Similarly, those strategies that may be useful in treating the dually diagnosed also are important and can become a part of the training curriculum. 


\section{ATTITUDES AND RESPONSIBILITY}

When confronted with the different clinical problems that dually diagnosed patients pose for both individual clinicians and service systems, a central issue is the question of responsibility. No matter where these patients initially present for treatment, with few exceptions they will invariably be referred to the mental health system. The nonpsychiatric professionals who have significant expertise and success in treating substance abuse disorders alone, also are significantly inexperienced in working with psychiatric disorders and may decline to work with these patients without help or guidance. Many private practitioners have demonstrated an unwillingness to work with the dually diagnosed. Community mental health centers, where many of these patients are seen, are typically overburdened and underfunded; because they may have minimal experience and limited staff to work effectively with this type of patient, responsibility for treatment often is shared with or transferred to the local drug and alcohol agency and there is little incentive to coordinate these services. As a result, many dual diagnosis patients are unwanted and they are all too aware of this.

There is not much merit to a system which can avoid responsibility for patients simply because they do not have an approved or acceptable condition for treatment. Differentiating between psychiatric illness and substance abuse disorders may be useful for prescribing treatment, but is artificial and arbitrary when it is used to restrict treatment. Psychiatrists have a significant role to play in leading the efforts to change this situation and can accept greater responsibility for the care of these patients. Psychiatrists-in-training have a unique opportunity to stimulate and influence those efforts, to benefit from the positive changes in the system, and to be a part of the process of research, education, and clinical practice that can develop to serve dual diagnosis patients more effectively.

If psychiatry is unable to assume greater responsibility for the dually diagnosed, then there is no other professional who is in a better position to do so, either. Why psychiatrists? Their background is sufficiently broad that, at least in theory, they should be capable of responding to the myriad problems that dual diagnosis patients often present with for treatment. Psychiatric illness and substance abuse are merely parts of a larger spectrum of mental health problems, which psychiatrists should have expertise in diagnosing and treating. In addition, their experience in interdisciplinary settings is an essential component to providing and integrating treatment for dual diagnosis patients.

Psychiatrists can become a constant and reliable element in the lives of these patients, which may otherwise be lacking and which may ultimately contribute to their improvement. Smaller social networks are associated with the comorbidity of substance abuse and psychopathology (23); if psychiatrists are unwilling or unable to work with the dually diagnosed, then that can only contribute to the isolation and poor social support many of them experience. Furthermore, psychiatrists-in-training are entering an era in which the efforts to destigmatize psychiatric illness are beginning to show results. By not accepting greater 
responsibility for working with the dually diagnosed, there is the risk of undermining those efforts and further stigmatizing yet another group of patients.

\section{CONCLUSIONS}

Dual diagnosis patients represent a formidable challenge for psychiatrists. The difficulty of these patients, the structure of the mental health system, the lack of experience and training, and other factors all conspire to make it more difficult to accept and to work with many of these patients, despite their very real needs. However, these factors do not make it impossible to treat the dually diagnosed. Nor should the clinical situation be so grim as to temper enthusiasm or limit therapeutic aggressiveness in working with them. The dually diagnosed are a diverse group of patients who can respond to treatment (24-27), but who also require flexibility, collaboration, and creativity as part of the approach to treatment.

The usual treatment paradigms that are applied to psychiatric illness or substance abuse disorders alone probably are not adequate for the dually diagnosed. Too often, noncompliance or poor treatment response are "blamed" on the patient. This neglects the very real disability that can result from their condition and assumes that a particular treatment approach is infallible. The psychiatrist-in-training is in a unique position not only to provide much needed clinical services for the dually diagnosed, but also to lobby for changes in training and in other administrative areas, which will have an impact on all types of services for these patients. There is an opportunity to provide leadership and creative energy in a problem area of psychiatry that has been poorly served. Hopefully, this opportunity can be used to begin to meet the challenges of working with dual diagnosis patients.

\section{REFERENCES}

1. Ridgely MS, Osher FC, Talbott JA: Chronic mentally ill young adults with substance abuse problems: Treatment and training issues. Mental Health Policy Studies Program, University of Maryland, October, 1987

2. Menicucci LD, Wermuth L, Sorensen J: Treatment providers' assessment of dualprognosis patients: Diagnosis, treatment, referral, and family involvement. Int J Addict 23:617-622, 1988

3. Davis DI: Differences in the use of substances of abuse by psychiatric patients compared with medical and surgical patients. J Nerv Ment Dis 172:654-657, 1984

4. Ross HE, Glaser FB, Germanson T: The prevalence of psychiatric disorders in patients with alcohol and other drug problems. Arch Gen Psychiatry 45:1023-1031, 1988

5. Hall RCW, Popkin MK, Devaul R, et al: The effect of unrecognized drug abuse on diagnosis and therapeutic outcome. Am J Drug Alcohol Abuse 4:455-465, 1977

6. Helzer JE, Pryzbeck TR: The co-occurrence of alcoholism with other psychiatric disorders in the general population and its impact on treatment. J Stud Alcohol 49:219-224, 1988 
7. Mirin SM, Weiss RD, Michael J, et al: Psychopathology in substance abusers and their families. Resident Staff Physician 34:61-65, 1988

8. Safer DJ: Substance abuse by young adult chronic patients. Hosp Community Psychiatry 38:511-514, 1987

9. Whitcup SM, Miller F: Unrecognized drug dependence in psychiatrically hospitalized elderly patients. J Am Geriat Soc 35:297-301, 1987

10. Whitlock FA, Lowrey JM: Drug-dependence in psychiatric patients. Med J Aust $1: 1157-1166,1967$

11. Cohen M, Klein DF: Posthospital adjustment of psychiatrically hospitalized drug users. Arch Gen Psychiatry 31:221-227, 1974

12. Reich R, Siegel L: The emergence of the bowery as a psychiatric dumping ground. Psychiatr Q 50:191-201, 1978

13. Galanter M, Castaneda R, Ferman J: Substance abuse among general psychiatric patients: Place of presentation, diagnosis, and treatment. Am J Drug Alcohol Abuse 14:211-235, 1988

14. Robbins E, Stern M, Robbins L, et al: Unwelcome patients: Where can they find asylum? Hosp Community Psychiatry 29:44-46, 1978

15. Solomon P: Receipt of aftercare services by problem types: Psychiatric, psychiatric/ substance abuse, and substance abuse. Psychiatr Q 58:180-188, 1986-87

16. Stuen MR, Solberg KB: Maximum hospital benefits vs. against medical advice: A comparative study. Arch Gen Psychiatry 22:351-355, 1970

17. LaPorte DJ, McLellan AT, O'Brien CP, et al: Treatment response in psychiatrically impaired drug abusers. Compr Psychiatry 22:411-419, 1981

18. McLellan AT, Luborsky L, Woody GE, et al: Predicting response to alcohol and drug abuse treatments: Role of psychiatric severity. Arch Gen Psychiatry 40:620-625, 1983

19. Mendelson EF: Alcohol-related psychiatric emergencies: Differences in characteristics between those arriving at a walk-in clinic during and outside office hours. Int J Addict 22:469-475, 1987

20. Gelberg L, Linn LS, Leake BD: Mental health, alcohol and drug abuse, and criminal history among homeless adults. Am J Psychiatry 145:191-196, 1988

21. Hasin D, Grant B, Endicott J: Treated and untreated suicide attempts in substance abuse patients. J Nerv Ment Dis 176:289-294, 1988

22. Murphy GE: Suicide and substance abuse. Arch Gen Psychiatry 45:593-594, 1988

23. Westermeyer J, Neider J: Social networks and psychopathology among substance abusers. Am J Psychiatry 145:1265-1269, 1988

24. Hellerstein DJ, Meehan B: Outpatient group therapy for schizophrenic substance abusers. Am J Psychiatry 144:1337-1339, 1987

25. Kofoed L, Kania J, Walsh T, et al: Outpatient treatment of patients with substance abuse and coexisting psychiatric disorders. Am J Psychiatry 143:867-872, 1986

26. Kranzler HR, Liebowitz NR: Anxiety and depression in substance abuse: Clinical implications. Med Clin North Am 72:867-885, 1988

27. Rounsaville BJ, Kosten TR, Kleber HD: Long-term changes in current psychiatric diagnoses of treated opiate addicts. Compr Psychiatry 27:480-498, 1986 